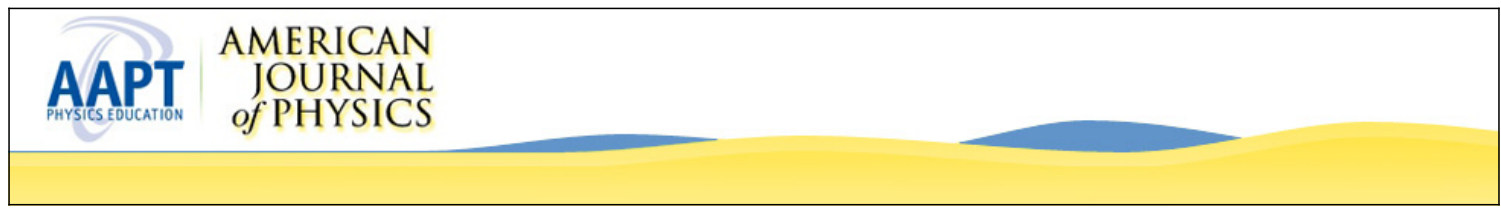

\title{
A simple demonstration of the Barkhausen effect
}

William Lonc

Citation: American Journal of Physics 60, 860 (1992); doi: 10.1119/1.17072

View online: http://dx.doi.org/10.1119/1.17072

View Table of Contents: http://scitation.aip.org/content/aapt/journal/ajp/60/9?ver=pdfcov

Published by the American Association of Physics Teachers

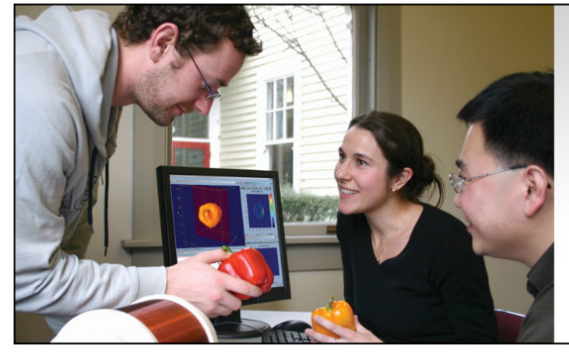

Teach NMR and MRI

Hands-on education with Terranova-MRI

Includes complete student guide with

12 experiments and online videos. 
The quantity $\gamma$ is an important thermodynamic quantity since it completely specifies the thermal properties of a dilute gas. Moreover, $\gamma$ may be interpreted microscopically through the equipartition of energy theorem as a measure of the number of thermally active degrees of freedom $f$ per molecule, by virtue of the relation

$$
\gamma=1+2 / f
$$

thus providing students with a simple but nonetheless important insight into the molecular basis of thermodynamics. In the case of a mixture of diatomic molecules such as air $f=5$ yielding $\gamma=1.4$. In addition to the significance of the experiment from the perspective of thermodynamics, it also offers an simple illustration of harmonic motion that can serve as the basis for further study and discussion.

More accurate methods for determining $\gamma$ exist. ${ }^{2}$ However, the present experiment is reasonably straightforward to do, and encourages the student to consider the wider applications of the graphical analysis of data as the method outlined above offers two independant determinations of $\gamma$ as well as an independant estimate of the volume $V_{0}$.

${ }^{1}$ Catalog numbers: Tube (37105), Glass Aspirator (37104).

${ }^{2} \mathrm{D}$. G. Smith, "Simple $C_{p} / C_{v}$ resonance apparatus for the physics teaching laboratory," Am. J. Phys. 47, 593-596 (1979).

\title{
A simple demonstration of the Barkhausen effect
}

\author{
William Lonc \\ Physics Department, Saint Mary's University, Halifax, N.S. B3H 3C3, Canada
}

(Received 9 March 1992; accepted 23 March 1992)

In an attempt to demonstrate induced emf to a noncalculus introductory physics class, it was surmised that a simple cassette tape player could be useful. The idea was to place the player in its "play" mode-but without a tapeand then to wave a magnetized nail or screwdriver past the player's pickup head. It was expected that an audible "click" or "thump" would be heard in the loudspeaker (of course, the volume would be turned up to maximum!).

The result was as expected, but it was also noticed that there was "white" noise being generated at the same time. This noise immediately recalled a phenomenon known as the Barkhausen effect, which pertains to discontinuous domain-wall motion in a ferromagnet. To make the noise more dramatic, a magnetron magnet was brought up, somewhat slowly, to within a few centimeters of the cas- sette player's pickup head. As the magnet was being moved toward and away from the pickup head, the resulting white noise (discontinuous domain-wall motion) was quite noticeable.

It would be surprising if this particular implementation of demonstrating the Barkhausen effect is all that new. However, the author does not recall seeing any discussion of this implementation in this Journal during the past several decades, so the hope is that this particular discussion of the demonstration at this time will be of some interest. A convenient account of the effect is given by Feynman et al. ${ }^{1}$

\footnotetext{
${ }^{1}$ R. P. Feynman, R. B. Leighton, and M. Sands, The Feynman Lectures on Physics Vol II (Addison-Wesley, Reading, MA, 1964) Chap. 37, pp. 9-10.
}

\section{HOW MANY PHYSICISTS HAVE READ THE PRINCIPIA?}

Very few persons in London read Descartes, whose works have in fact become totally useless. Newton also has very few readers, because it requires great knowledge and sense to understand him. Everybody however talks about him.

Voltaire, quoted in Let Newton Be, edited by John Fauvel, Raymond Flood, Michael Shortland, and Robin Wilson (Oxford, New York, 1988), p. 3. 